\title{
Assessment of Knowledge of Radiographic Students about Radiation Protection Devices, Their Use and Handling
}

\author{
Lakshmi Yadav', Navreet Boora², Raushan Kumar ${ }^{3}$, Niraj Kumar $\mathrm{Sah}^{4}$ \\ ${ }^{1}$ M.Sc. (MRIT) Research Follow, Radiological Imaging Techniques, TMU, Moradabad, Uttar Pradesh India. \\ ${ }^{2,3,4}$ Assistant Professor, Radiological Imaging Techniques, Faculty of College of Paramedical science, TMU, \\ Moradabad, Uttar Pradesh, India. \\ Corresponding Author: Lakshmi Yadav
}

\begin{abstract}
Aim: The aim of this study to assess the knowledge of radiographic students about radiation protection devices, their use and handling.

Methods: A prospective, questionnaire-based study was carried out in Department of Radiological and Imaging Techniques. A validated questionnaire was circulated among undergraduate and postgraduate Radiographic students.

Result: Out of 169 participants was $150(88.7 \%)$ of undergraduate, postgraduate and diploma students of radiological and imaging techniques filled questionnaire in this study. To assess knowledge about radiation protection devices, their use and handling, which they gain during theory classes and from hospital posting. There were $58(38.7 \%)$ were female and $92(61.3 \%)$ were male.
\end{abstract}

Conclusion: Study concluded that there should be proper theory classes for the conduction of knowledge about radiation protection devices, their use and handling in radiology department. Training session and teaching standards should be taken in account for not only the number of hours required to obtain the knowledge with the equipment required to run the classes in the simulation-based learning environment. This questionnaire-based survey demonstrates that up-to-date radiation protection devices, their use and handling skill in among radiography students of college of paramedical sciences were not sufficient, this should be improved by the well-designed training and theoretical sessions. From this study, we suggest that all members of the health care community should attend the webinars, guest lectures and training sessions about knowledge of radiation protection devices, their use and handling in radiology department.

Keywords: Radiation protection devices, Lead equivalent, X-ray, Radiology department

\section{INTRODUCTION}

Radiation is a form of energy that comes from source, which can travel one place to another in vacuum at the speed of light i.e. without any medium. Radiations are of two types:

1. Ionizing Radiation: In ionizing radiation Gamma rays and $\mathrm{X}$-rays are used.

2. Non ionizing Radiation: In non ionizing radiation electromagnetic and radiofrequency wave are used.

Since the $\mathrm{X}$ - ray was discovered by Wilhelm Conrad Rontgen in 1895 on Friday 8 November. ${ }^{[1]}$ It is essential part of health care diagnosis and interventional. Ionizing radiations are utilized in interventional fluoroscopy, CT etc. Approximately every year, greater than two thousand five hundred millions diagnostic radiology examinations, 5.5 millions radiotherapy and 32 millions nuclear medicine session are performed worldwide. There can be a harmful result at low doses of ionizing radiation $^{[8]}$. 
In radiology department ionizing radiation is used which is most important tools used in medical imaging. Ionizing radiation which is used in radiology departments has dangerous effect on living system. Radiation produced various kind of harm that is untreatable. Ionizing radiation may effect on CNS, gastrointestinal system, reproductive system or even entire body. Somatic effect can be develop immediately after exposure but Ionizing genetic effect must not appear immediately it appear in next generation. So radiation worker shielding is compulsory when radiation is used during any procedure. Radiation worker shield are compulsory for all diagnostic imaging departments. Most widely utilized ionizing radiation in medicine and enterprises that may present a enormous fitness threat via way of means of inflicting microscopic harm residing tissue. Radiation protection devices are used in radiology department for shielding of people from dangerous results of radiation. Because ionizing radiation cause most of the harmful effects like cataract, skin erythematic, organ atrophy and cancer etc. Radiation protection devices consist;

- Lead apron

- Thyroid shield

- Gonad shield

- Lead goggles

- Lead gloves

Every person working in the radiation room must wear a personnel protection device, when the radiographic unit is operated. For physician, patient and staff in many department including radiology, surgery, and Interventional cardiology radiation safety is concern. During fluoroscopic procedure radiation is emitted which is responsible for the greatest radiation dose for medical staff. Because most of ionizing radiation exposure in medical setting arises from fluoroscopy imaging, which uses $\mathrm{X}$ rays to obtained dynamic imaging. During $\mathrm{X}$-ray exposure all staff of radiographic room stands behind a mobile protective barrier or use personnel protective devices like lead apron which cover the body part . The whole protective barrier are used is not less than $0.25 \mathrm{~mm}$ of lead equivalent. When standing in the primary beam the personnel protective devices thickness is $0.5 \mathrm{~mm}$ to $0.25 \mathrm{~mm}$ for scattered radiation .Worker, that not standing on the primary beam have required least $0.25 \mathrm{~mm}$ of lead equivalent shield.

\section{CARE AND USE OF RADIATION PROTECTION DEVICES}

Care of the radiation safety devices has to hold the lead integrity. Dropping, piling, frequently fall down, wrongfully storing can fracture the inner layer of lead, influence the protective and integrity ability thus proper checking and storage is required for its proper utilize .Radiation protection devices should be checked at least on an annual basis for their shielding integrity.

\section{STORAGE}

Lead apron, thyroidshield, gonad shield, side shield, gloves shield and another safety device would be both stored on hangers or flat in well designed racks or to inhibit flaws along with inner cracks. The internal cracks in the lead lining can develop at the folds, reducing the useful life of the devices.

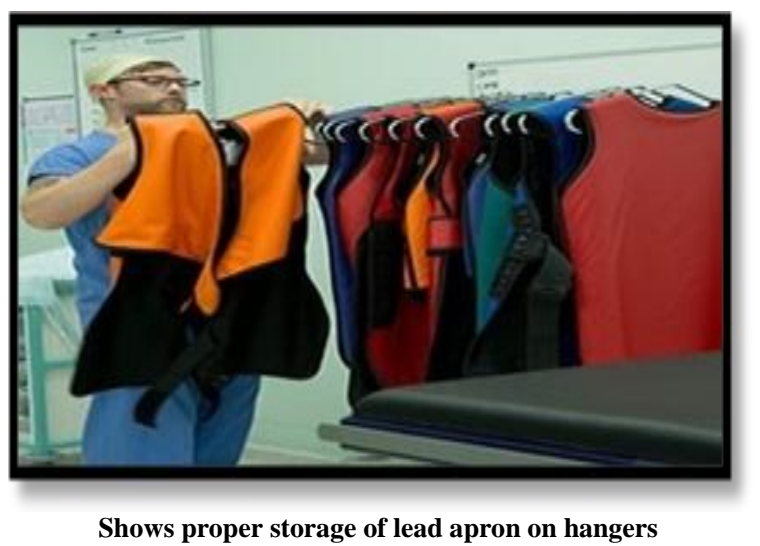

Any items displaying break in the lead lining should be replaced .A Pb apron may also get changed if flaw is larger than $15 \mathrm{~mm} 2$ in areas close to critical organs. May be thyroid shield also ought to get replaced if flaw is greater than $11 \mathrm{~mm} 2{ }^{[7]}$ 


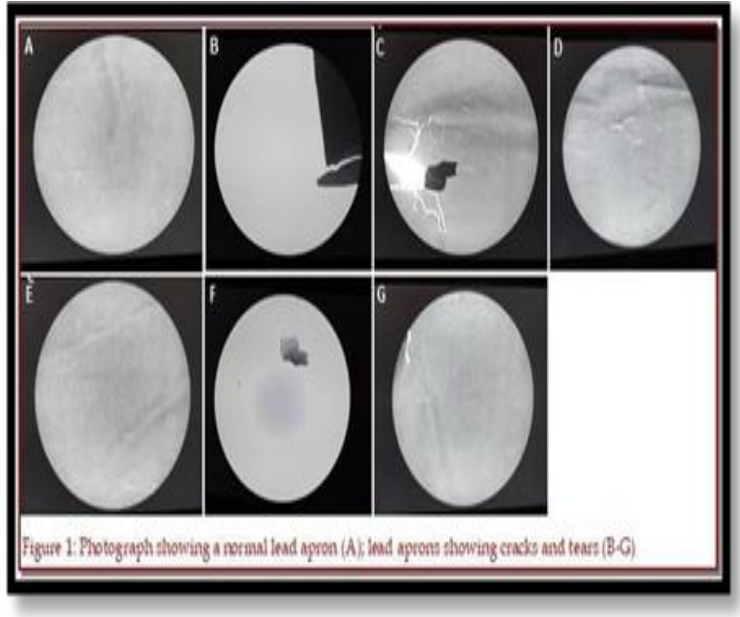

Photograph showing a normal lead apron (A); lead aprons showing cracks and tears (B-G)

\section{METHOD AND MATERIAL}

STUDY TYPE: A prospective, questionnaire based study was carried out in Department of Radiological and Imaging Techniques at college of paramedical sciences. This study was based on Assessment of Knowledge of Radiographic Students about Radiation Protection Devices, Their Use and Handling. To check the knowledge of undergraduate students, Post graduate and diploma (CT and X-Ray) Radiographic Students about Radiation Protection Devices, their Use and Handling.

STUDY DESIGN: This study was designed to be check the knowledge Radiography undergraduate second year, final year and Post graduate First year and final year and Diploma CT 2nd year and X-ray 2nd year students in the college of paramedical sciences, Teerthanker Mahaveer University, Moradabad, Uttar Pradesh, India.

STUDY AREA: Radiological and Imaging Techniques students College of Paramedical Sciences, Teerthanker Mahaveer University Moradabad, Uttar Pradesh, India.

STUDY DURATION: This prospective questionnaire based study was conducted out for the time period of one year from April 2020 to May 2021 at College of Paramedical Sciences, Teerthanker Mahaveer University Moradabad, Uttar Pradesh, India.

\section{SELECTION CRITERIA}

- Inclusion Criteria

1. BRIT 4th Semester

2. BRIT 6th Semester

3. MRIT 2nd Semester

4. MRIT 4thSemester

5. Diploma Computed Tomography 2nd year

6. Diploma X-ray 2nd year

- Exclusion Criteria

1. BRIT 2nd Semester

2. Diploma in X-ray 1styear

3. Diploma in Computer Tomography 1styear

4. Diploma in Magnetic Resonance Imaging 1 st and 2ndyear

\section{STUDY POPULATION}

The study population consisted of Radiography students excluding the students who fell under exclusion criteria. The size of the students was 150 of undergraduate, postgraduate and diploma of Radiological and imaging techniques. A probability sampling method was employed while collecting samples.

\section{METHOD OF DATA COLLECTION}

A validated questionnaire was conducted among undergraduate, postgraduate and diploma Radiography students. The survey included multiple choice questions (MCQs) related to demographic characteristics (Age, Gender), academic qualification and Knowledge about radiation protection devices, their use and handling.

\section{STATISTICAL ANALYSIS}

The data collected was compiled, tabulated, graphical, analyzed and subjected to statistical tests. Analysis was done using Google forms.

\section{RESULT}

Out of total 169 participants was $150(88.7 \%)$ of undergraduate, postgraduate and diploma students of radiological and imaging techniques filled questionnaire in this study. 


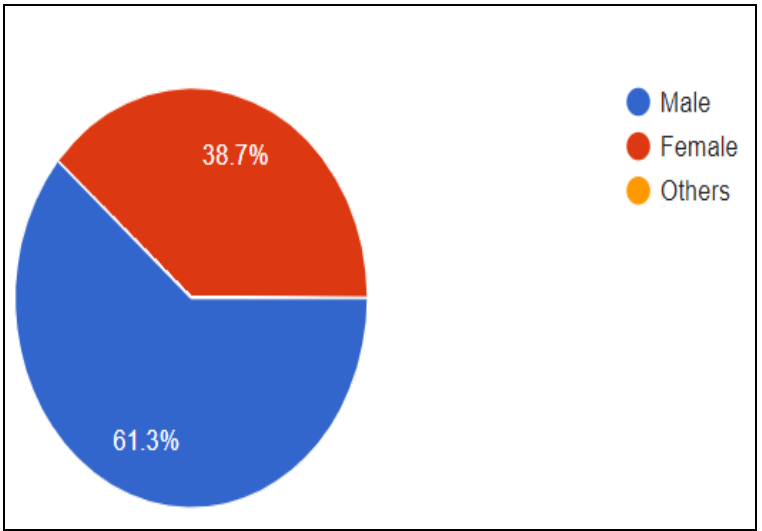

Pie chart shows the ratio of male and female participants

To assess knowledge about radiation protection devices, their use and handling ,which they gain during theory classes and from hospital posting .There were 58(38.7\%) were female and $92(61.3 \%)$ were male.

In 150 respondent ,19(12.7\%) were students of MRIT 4th semester, $13(8.7 \%)$ were students of MRIT 2nd semester ,51(34\%) were students of BRIT 6thsemester, 57(38\%) were students of BRIT4th semester , $8(5.3 \%)$ were students of $\mathrm{x}$ ray 2 nd year and $2(1.3 \%)$ were students of diploma C.T 2nd year

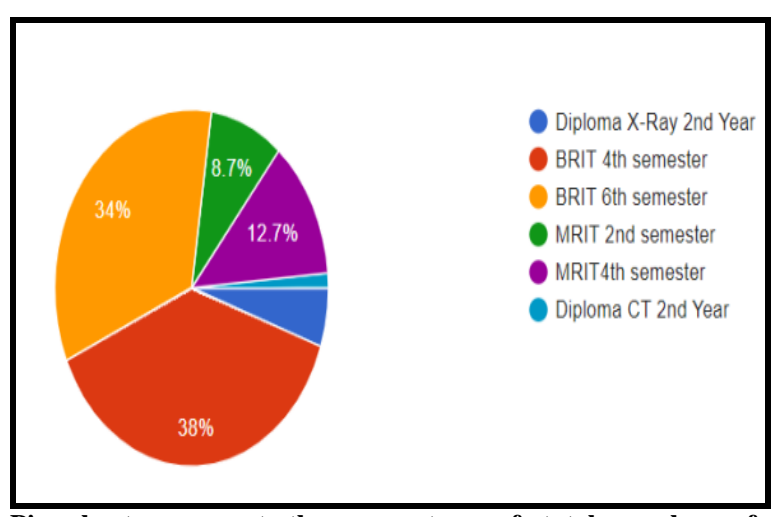

Pie chart represent the percentage of total number of respondents according to course

In this study to assess the knowledge of students from under graduation, post graduation and diploma in radiology imaging technique Knowledge about radiation protection devices, their use and handling radiology department is a serious issue which need to be addressed promptly and carefully. Calculated the mean value of respondents who give correct answer. The analysis of the collected data has allowed formulating the following conclusion. Knowledge about radiation protection devices, their use and handling in BRIT 4th semester students had insufficient knowledge $57.3 \%$, BRIT 6th semester students had average knowledge $67.5 \%$, MRIT 2nd semester students had good knowledge 74\%, MRIT 4th semester students had good knowledge $79.1 \%$ and diploma students had insufficient knowledge $56 \%$.

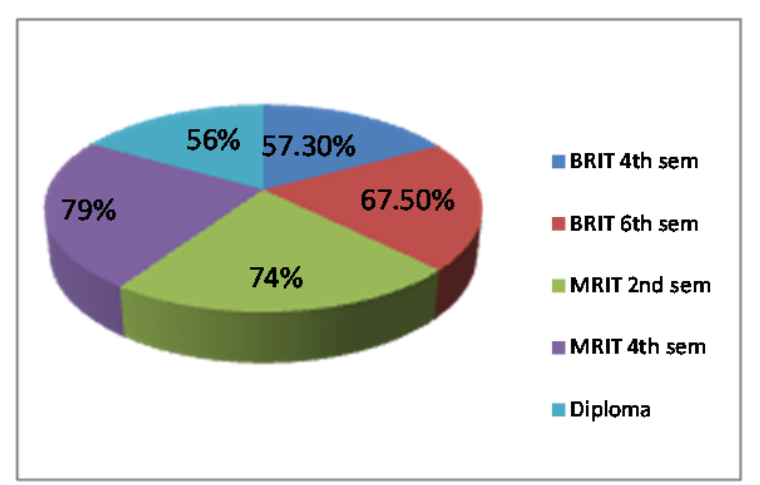

Pie chart shows the mean value of respondents

\begin{tabular}{|l|l|}
\hline Total Result & Mean Values \\
\hline BRIT $4^{\text {th }}$ & $56 \%$ \\
\hline BRIT $6^{\text {th }}$ & $67.50 \%$ \\
\hline MRIT $2^{\text {nd }}$ & $74 \%$ \\
\hline MRIT $4^{\text {th }}$ & $79 \%$ \\
\hline Diploma & $56 \%$ \\
\hline
\end{tabular}

\section{DISCUSSION}

In this study to assess the knowledge of students from under graduation, post graduation and diploma in radiology imaging technique Knowledge about radiation protection devices, their use and handling radiology department is a serious issue which need to be addressed promptly and carefully. Calculated the mean value of respondents who give correct answer. The analysis of the collected data had allowed formulating the following conclusion. Knowledge about radiation protection devices ,their use and handling in BRIT 4th semester students had insufficient knowledge $57.3 \%$, BRIT 6th semester students had average knowledge 67.5\%, MRIT 2nd semester students had good knowledge 74\%, MRIT 4th semester students had good knowledge $79.1 \%$ and 
Lakshmi Yadav et.al. Assessment of knowledge of radiographic students about radiation protection devices, their use and handling.

diploma students had insufficient knowledge $56 \%$.

\section{CONCLUSION}

Study concluded that there should be proper theory classes for the conduction of knowledge about radiation protection devices, their use and handling in radiology department. Training session and teaching standards should be taken in account for not only the number of hours required to obtain the knowledge with the equipment required to run the classes in the simulation-based learning environment. This questionnaire based survey demonstrate that up-to-date radiation protection devices, their use and handling skill in among radiography students of college of paramedical sciences were not sufficient, this should be improved by the well designed training and theoretical sessions. From this study, we suggest that all members of the health care community should attend the webinars, guest lectures and training sessions about knowledge of radiation protection devices, their use and handling in radiology department.

\section{Acknowledgement: None}

\section{Conflict of Interest: None}

\section{Source of Funding: None}

\section{REFERENCES}

1. Bhargava S. Textbook of Radiology for Residents and Technicians. 4th ed. New Delhi: Satish Kumar Jain for CBS Publisher; 2011.

2. Thayalan K. Textbook Of Radiological Safety. 1st ed. New Delhi: Jaypee Brother Medical Publisher; 2010.

3. Omojola, A. D., Akpochafor, M. O., Adeneye, S. O., \&Aniekop, U. P. (2019). Radiographic assessment of protective aprons and dose simulation to personnel. Journal of Radiation and Cancer Research, 10(2), 117.

4. Daniel, O. A., \& Xavier, I. C. (2018). Integrity test of lead apron and its effect on personnel and carers. Bangabandhu
Sheikh Mujib Medical University Journal, 11(1), 34-37.

5. Hu, P., Kong, Y., Chen, B., Liu, Q., Zhuo, W., \& Liu, H. (2017). Shielding effect of lead glasses on radiologists' eye lens exposure in interventional procedures. Radiation protection dosimeters, 174(1), 136-140.

6. Lakhwani, O. P., Dalal, V., Jindal, M., \& Nagala, A. (2019). Radiation protection and standardization. Journal of clinical orthopaedics and trauma, 10(4), 738-743.

7. Kuppusamy, T., 2017. Basic Radiological Physics. [S.L.]: Jaypee Brothers Medical P

8. Kazempour, M., Saeedimoghadam, M., Shooli, F. S., \& Shokrpour, N. (2015). Assessment of the radiation attenuation properties of several lead free composites by Monte Carlo simulation. Journal of biomedical physics \& engineering, 5(2), 67.

9. Livingstone, R. S., \& Varghese, A. (2018). A simple quality control tool for assessing integrity of lead equivalent aprons. The Indian journal of radiology \& imaging, 28(2), 258.

10. Jones, A. K., \& Wagner, L. K. (2013). On the (f) utility of measuring the lead equivalence of protective garments. Medical physics, 40(6Part1), 063902.

11. Iball, G. R., Kennedy, E. V., \&Brettle, D. S. (2008). Modelling the effect of lead and other materials for shielding of the fetus in CT pulmonary angiography. The British journal of radiology, 81(966), 499-503.

12. Kim, S. C., Choi, J. R., \&Jeon, B. K. (2016). Physical analysis of the shielding capacity for a lightweight apron designed for shielding low intensity scattering X-rays. Scientific reports, 6(1), 1-7.

13. Hubbert, T. E., Vucich, J. J., \& Armstrong, M. R. (1993). Lightweight aprons for protection against scattered radiation during fluoroscopy. AJR. American journal of roentgenology, 161(5), 1079-1081. 
Lakshmi Yadav et.al. Assessment of knowledge of radiographic students about radiation protection devices, their use and handling.

14. Finnerty, M., \& Brennan, P. C. (2005).

Protective aprons in imaging departments: manufacturer stated lead equivalence values require validation. European radiology, 15(7), 1477-1484.

15. Lambert, K., \& McKeon, T. (2001). Inspection of lead aprons: criteria for rejection. Health physics, 80, S67-S69

How to cite this article: Yadav L, Boora N, Kumar R et.al. Assessment of knowledge of radiographic students about radiation protection devices, their use and handling. International Journal of Research and Review. 2021; 8(6): 277-282. DOI: https:// doi.org/10.52403/ijrr.20210634 